\title{
System for measuring vacuum-pump performance using the standard throughput method
}

\author{
Sheng-Jui Chen, Sheau-Shi Pan, Ta-Chang Yu \\ Center for Measurement Standards, Industrial Technology Research Institute, Hsinchu, 30011, Taiwan, R.O.C.
}

\begin{abstract}
Ultimate pressure of a vacuum system is determined by two parameters, namely the total gas load of vacuum system and the pumping speed (volume flow rate) of vacuum pump. After the total gas load of a system is estimated, the required pumping speed can be set. In this study, we constructed a system for measuring the pumping speed of vacuum pump according to ISO 21360-1:2012, in which three methods are described, i.e. the throughput method, the orifice method and the pump-down method. The vacuum pump under test is designed to be used in low vacuum range for evacuating a chamber at high pumping speed. For this reason, the throughput method was selected as the main method. The system consists of pressure gauges, thermometers, a flow meter and a test chamber. The system was used to measure the pumping speed at the inlet of the vacuum pump at several pressure points. We present the system setup, uncertainty evaluation and vacuum-pump performance results of this work.
\end{abstract}

\section{Section: RESEARCH PAPER}

Keywords: vacuum-pump performance; pumping speed; throughput; vacuum calibration; volume flow rate

Citation: Sheng-Jui Chen, Sheau-Shi Pan, Ta-Chang Yu, System for measuring vacuum-pump performance using the standard throughput method, Acta IMEKO, vol. 7, no. 1, article 12, March 2018, identifier: IMEKO-ACTA-07 (2018)-01-12

Section Editor: Jorge Torres-Guzman, CENAM - Centro Nacional de Metrologia, Santiago de Querétaro, Mexico

Received July 12, 2017; In final form November 15, 2017; Published March 2018

Copyright: (C) 2018 IMEKO. This is an open-access article distributed under the terms of the Creative Commons Attribution 3.0 License, which permits unrestricted use, distribution, and reproduction in any medium, provided the original author and source are credited

Funding: This work was supported by Bureau of Standards, Metrology \& Inspection, M.O.E.A., R.O.C.

Corresponding author: Sheng-Jui Chen, e-mail: sj.chen@itri.org.tw

\section{INTRODUCTION}

The pumping speed is one of performance parameters of a vacuum pump. It specifies the volume flow rate at which gas is evacuated through the pump inlet port. The pumping speed is pressure and gas dependent. It has a dimension of volume per unit time such as $\mathrm{m}^{3} / \mathrm{s}, \mathrm{L} / \mathrm{s}$ or $\mathrm{m}^{3} / \mathrm{h}$ (cubic meter per hour, $\mathrm{CMH}$ ). Another important parameter is the ultimate pressure which is the lowest pressure a pump can achieve. In most applications, the pumping speed given in the pump specification is usually sufficient for designing a vacuum system. However, in some applications, there are still needs to measure the pumping speed in order to verify the design or to check whether the pump is properly installed and conditioned. In this work, we measured the pumping speed of a screw pump according to the standard throughput method described in ISO 21360-1 [1]. The screw pump is installed in a semiconductor fabrication building and designed to evacuate gas at a very high speed. To verify the pump performance on site, we designed and fabricated a pumping speed measurement system to fit this purpose. In the following sections, we introduce the principle of measurement, experimental setup and the results of this work.

\section{MEASUREMENT PRINCIPLE AND EXPERIMENTAL SETUP}

Since mass is conserved in a flow system, the rate of change of gas mass is the same at any cross section in the flow system. Using ideal gas equation, the rate of change of gas mass can be written as:

$m\left(\frac{d N}{d t}\right)=m \frac{d}{d t}\left(\frac{P V}{k_{B} T}\right)$,

where $m$ is the molar mass of the gas, $N$ is the number of gas molecules in a given volume $V, P$ is the absolute pressure, $T$ is the absolute temperature and $k_{B}$ is the Boltzmann constant. Assuming the number $N$ of gas molecules is also conserved, i.e. no chemical reactions between gas molecules, and the 
temperature $T$ is the same in the given volume, the rate of change of gas molecules is written as:

$\frac{d N}{d t}=\frac{1}{k_{B} T} \frac{d(P V)}{d t}=\frac{Q}{k_{B} T}$,

where $Q=d(P V) / d t$ is the throughput of the gas. When pressure is held at a constant value, the throughput can be expressed as

$Q=P \frac{d V}{d t}=P q_{V}$,

where $q_{V}$ is the volume flow rate.

According to the throughput method in ISO 21360-1, we set up a vacuum-pump pumping speed measurement system to testing the screw pump (Sullair VS20-75). The measurement system consists of a vacuum chamber, a connection vacuum pipe, a capacitive absolute pressure gauge (MKS 690A13TRA), a portable pressure gauge (RUSKA 6220-19) and a rotary position gas flowmeter (Elster Instromet IRM-A G160). Each instrument used in the system is traceable to the corresponding standard in National Measurement Laboratory (NML). The schematic is shown in Figure 1. Considering the height of the screw pump and the easiness of installation, the connection vacuum pipe was used in the practical setup, making the setup

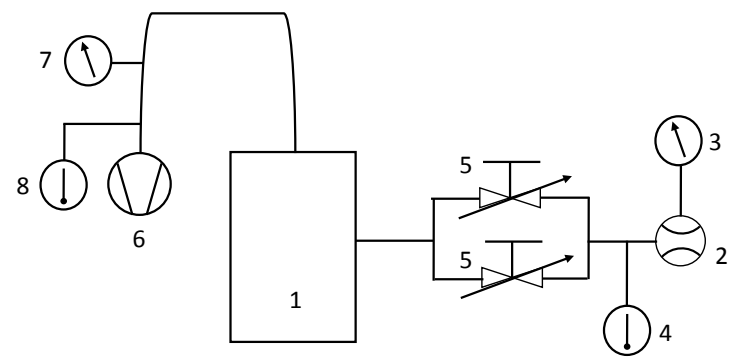

Key:

$\begin{array}{llll}1 & \text { Vacuum chamber } & 5 & \text { Gas inlet valve } \\ 2 & \text { Flow meter } & 6 & \text { Pump under test } \\ 3 & \text { Pressure gauge } & 7 & \text { Capacitive pressure gauge } \\ 4 & \text { Thermometer } & 8 & \text { thermometer }\end{array}$

Figure 1. Schematic of the pumping speed measurement system. slightly deviate from the standard configuration. However, the pressure and temperature were measured at positions very close to the air inlet of the screw vacuum, and therefore the conductance of the vacuum pipe will not affect the measured pumping speed at the air inlet. Figure 2 shows the practical configuration of the measurement system, along with parameters to be measured at corresponding positions. The parameters include pressures $p_{0}, p_{1}$ and temperatures $T_{0}, T_{D}$ at the input port of the flowmeter and at the air inlet of the pump under test, respectively. The gas flowmeter is a high accuracy positive displacement meter which is insensitive to changes in the relative density of the gas to be measured. A fixed volume $v_{V F}=1 / 806.313 \mathrm{~m}^{3}$ of the gas is displaced by each revolution of rotors inside the flowmeter. A frequency counter (HP $53132 \mathrm{~A}$ ) was used to measure the frequency of the rotor revolution signal output from the flowmeter. From the measured frequency $f_{V F}$, the volume flow rate $q_{V F}\left(\mathrm{~m}^{3} / \mathrm{h}\right)$ at the flowmeter can be obtained by $q_{V F}=3600 \cdot v_{V F} \cdot f_{V F}$. To allow the correct use of the flowmeter, the measurements were made with increasing pressure.

To begin the measurement, firstly the base pressure $p_{b}$ of the system was determined by evacuating the system with all gas inlet valves closed and observing the pressure $p_{1}$. When no pressure drop was observed, the final pressure $p_{1}$ was the base pressure $p_{b}$. The pressure range for pumping speed measurement was from 10 Torr to 110 Torr with an increment of 10 Torr. The adjustable gas inlet valve was opened to make pressure $p_{1}$ equal to the set pressure point. At each pressure point, all the measurement parameters were repeatedly acquired and statistically processed by a LabVIEW program.

\section{DATA ANALYSIS AND RESULTS}

From equation (2) and (3), the rate of change of gas molecules at the input port of the flowmeter is the same as that at the air inlet of the screw pump:

$\frac{p_{0}}{k_{B} T_{0}} q_{V F}=\frac{\left(p_{1}-p_{b}\right)}{k_{B} T_{D}} q_{V}$

where the base pressure $p_{b}$ is introduced in the equation to

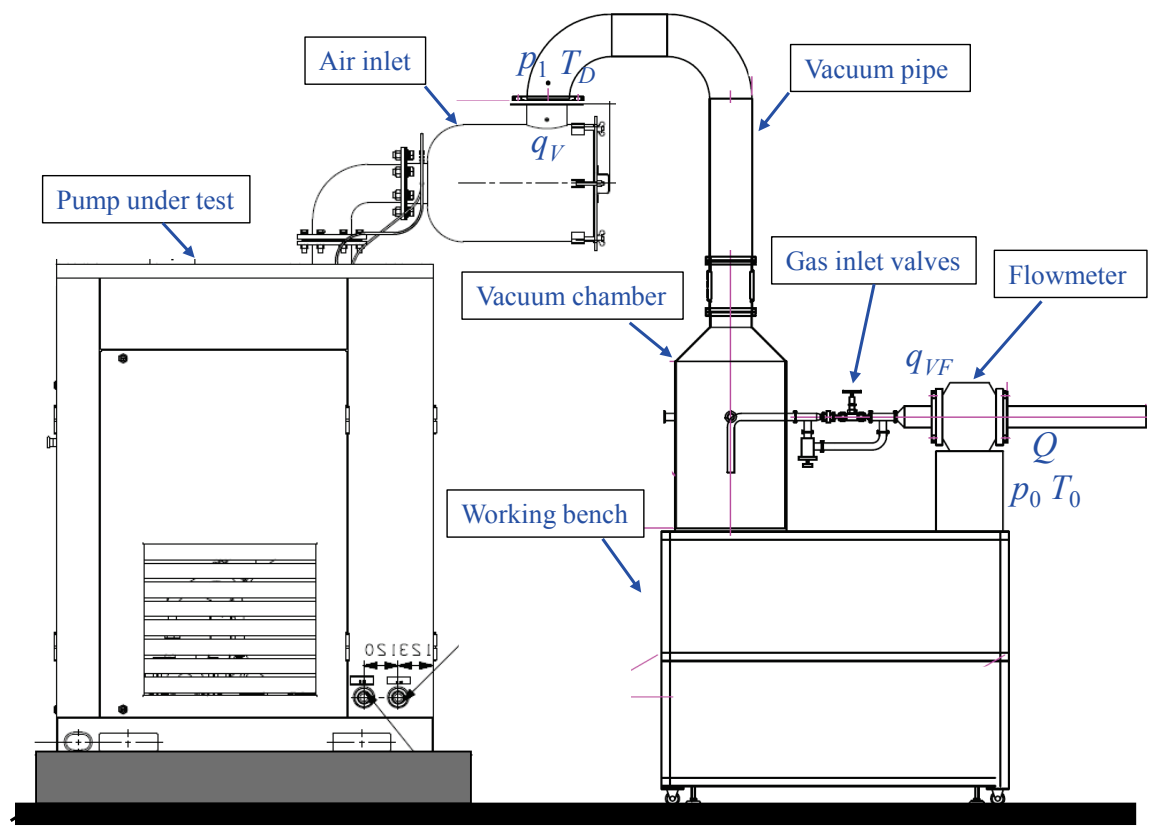

Figure 2. Practical configuration of the measurement system. 
reflect the fact that there will be no gas flow when the ultimate pressure $p_{b}$ of the system is reached. The pumping speed $q_{V}$ at the air inlet is calculated as

$$
q_{V}=\frac{q_{V F} p_{0} T_{D}}{T_{0}\left(p_{1}-p_{b}\right)} \text {. }
$$

The uncertainty of pumping speed is estimated by [2]

$u_{q_{V}}=q_{V}\left[\begin{array}{l}\left.\left(\frac{u_{q_{V F}}}{q_{V F}}\right)^{2}+\left(\frac{u_{p_{0}}}{p_{0}}\right)^{2}+\left(\frac{u_{T_{D}}}{T_{D}}\right)^{2}\right]^{1 / 2}, \\ +\left(\frac{u_{T_{0}}}{T_{0}}\right)^{2}+\frac{u_{p_{1}}^{2}+u_{p_{b}}^{2}}{\left(p_{1}-p_{b}\right)^{2}}\end{array}\right]^{2}$

where $u_{\mathrm{i}}$ is the uncertainty of parameter i. One of the measurement results are listed in Table 1. The highest pumping speed was measured to be $(1661 \pm 45) \mathrm{m}^{3} / \mathrm{h}$, and this result agrees with the specification of the screw pump. Two pumping performance curves are measured and plotted in Figure 3 along with the data given in the specification of the screw pump.

\section{DISCUSSION}

In this work, we demonstrated the on-site measurement of the pumping performance of the screw pump used in semiconductor industry. The standard throughput method was used in this measurement. The measured performance curve is compatible with the specification of the pump under test. The relative expanded uncertainties of the results are all within $5 \%$ meeting the requirement stated in ISO 21360-1:2012.

\section{REFERENCES}

[1] ISO 21360-1:2012, Vacuum technology - Standard methods for measuring vacuum-pump performance - Part 1: General description.

[2] ISO/IEC Guide 98-3:2008, Uncertainty of measurement — Part 3: Guide to the expression of uncertainty in measurement.

Table 1. Pumping speed measurement results. The base pressure $p_{b}$ was measured to be 2.75 Torr.

\begin{tabular}{|c|c|c|c|c|c|c|c|c|c|c|}
\hline $\begin{array}{r}p_{1} \\
\text { (Torr) }\end{array}$ & $\begin{array}{l}p_{1} \text { STD } \\
\text { (Torr) }\end{array}$ & $f_{V F}(H z)$ & $\begin{array}{c}f_{V F} s t d \\
(H z)\end{array}$ & $\begin{array}{r}q_{v F} \\
\left(\mathrm{~m}^{3} / \mathrm{h}\right)\end{array}$ & $\begin{array}{c}T_{0} \\
\text { (deg. C) }\end{array}$ & $\begin{array}{c}T_{0} \text { STD } \\
\text { (deg. C) }\end{array}$ & $\begin{array}{c}T_{D} \\
\text { (deg. C) }\end{array}$ & $\begin{array}{r}T_{D} \text { STD } \\
\text { (deg. C) }\end{array}$ & $q_{v}\left(\mathrm{~m}^{3} / \mathrm{h}\right)$ & $\begin{array}{l}\text { Expanded uncertainty } \\
\text { of } q_{v}\left(\mathrm{~m}^{3} / \mathrm{h}\right)\end{array}$ \\
\hline 9.95 & $3.53 e-2$ & 2.19 & $1.27 \mathrm{E}-02$ & 9.76 & 22.75 & $9.24 \mathrm{E}-03$ & 21.68 & 8.04E-03 & 1007 & 42 \\
\hline 19.99 & $2.10 \mathrm{e}-2$ & 6.62 & $1.04 \mathrm{E}-02$ & 29.56 & 22.76 & $6.46 \mathrm{E}-03$ & 21.69 & $2.42 \mathrm{E}-03$ & 1274 & 39 \\
\hline 29.96 & 2.49E-02 & 11.42 & $1.46 \mathrm{E}-02$ & 51.01 & 22.76 & $1.44 \mathrm{E}-03$ & 21.64 & $2.05 \mathrm{E}-03$ & 1392 & 40 \\
\hline 39.89 & 3.80E-02 & 16.36 & 1.79E-02 & 73.06 & 22.74 & 8.82E-04 & 21.56 & $6.20 \mathrm{E}-03$ & 1459 & 41 \\
\hline 49.85 & $3.46 \mathrm{E}-02$ & 21.65 & $1.36 \mathrm{E}-02$ & 96.67 & 22.7 & $1.79 \mathrm{E}-03$ & 21.37 & $2.92 \mathrm{E}-03$ & 1521 & 42 \\
\hline 59.90 & $3.23 \mathrm{E}-02$ & 27.06 & $4.00 \mathrm{E}-02$ & 120.80 & 22.68 & $6.48 \mathrm{E}-03$ & 21.26 & $4.18 \mathrm{E}-04$ & 1565 & 43 \\
\hline 69.70 & $4.20 \mathrm{E}-02$ & 32.34 & $8.25 \mathrm{E}-02$ & 144.37 & 22.51 & $5.12 \mathrm{E}-04$ & 21.22 & $4.27 \mathrm{E}-03$ & 1595 & 44 \\
\hline 79.80 & $4.90 \mathrm{E}-02$ & 37.61 & 7.71E-02 & 167.91 & 22.43 & $2.16 \mathrm{E}-03$ & 21.25 & 4.92E-03 & 1611 & 44 \\
\hline 90.12 & 4.07E-02 & 43.22 & $2.79 \mathrm{E}-02$ & 192.98 & 22.35 & $1.59 \mathrm{E}-03$ & 21.16 & $1.55 \mathrm{E}-03$ & 1631 & 44 \\
\hline 99.75 & 5.07E-02 & 48.62 & $5.02 \mathrm{E}-02$ & 217.10 & 22.26 & 4.36E-03 & 21.13 & 5.16E-04 & 1651 & 44 \\
\hline 106.65 & $6.29 \mathrm{E}-02$ & 52.43 & $9.08 \mathrm{E}-02$ & 234.08 & 22.18 & 1.39E-03 & 21.12 & $4.18 \mathrm{E}-03$ & 1661 & 45 \\
\hline
\end{tabular}

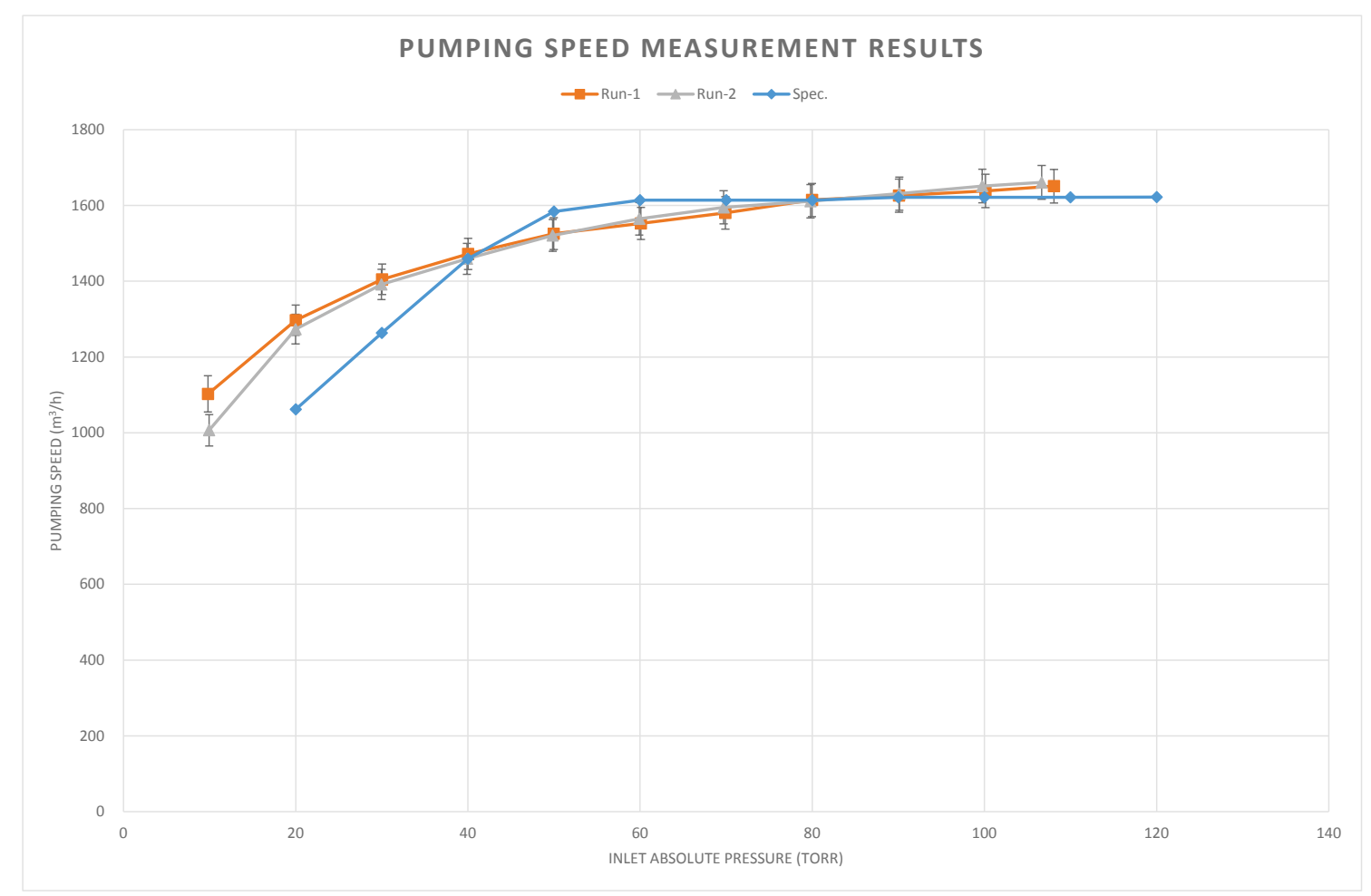

Figure 3. Two pumping performance curves measured in this study. 